\title{
The effects of shelf display on online grocery choices
}

Els Breugelmans, Katia Campo and Els Gijsbrechts

DEPARTMENT OF MARKETING AND ORGANISATION STUDIES (MO) 


\title{
The effects of shelf display on online grocery choices
}

\author{
Els Breugelmans \\ Maastricht University \\ Katia Campo \\ Catholic University of Leuven \\ Els Gijsbrechts \\ University of Tilburg
}

April 2006

\begin{abstract}
Acknowledgments
We acknowledge the financial support of the Fund for Scientific Research, Flanders (FWO-Vlaanderen). The authors are much indebted to both the respondents that pre-tested the experimental design and the respondents that participated in the research. They further thank Patrick De Pelsmacker, Gilles Laurent, Annouk Lievens, Patrick Van Kenhove, Walter van Waterschoot and Philippe Verbeeck, two anonymous reviewers and the editor for their helpful suggestions on earlier versions of this manuscript.
\end{abstract}

Els Breugelmans is Assistant Professor at the Faculty of Economics and Business Administration, Department of Marketing, Maastricht University. Address: P.O. Box 616, 6200 MD Maastricht, The Netherlands. Tel. +31433883855; Fax +31-433884918. E-mail: e.breugelmans@mw.unimaas.nl

Katia Campo is Associate Professor of Marketing at the Faculty of Economics and Applied Economics, Department of Marketing and Strategy, Catholic University Leuven. Address: Naamsestraat 69, 3000 Leuven, Belgium. Tel. +32-16326819; Fax +32-16326732. E-mail : katia.campo@econ.kuleuven.be

Els Gijsbrechts is Professor of Marketing at the Faculty of Economics and Business Administration, Department of Marketing, University of Tilburg. Address: P.O. Box 90153, 5000 LE Tilburg, The Netherlands. Tel. +31134668224; Fax.+31-134668354. E-mail: E.Gijsbrechts@uvt.nl 


\title{
Shelf Sequence and Proximity Effects on Online Grocery Choices
}

\begin{abstract}
Research on shelf effects in traditional grocery stores has shown that a product's absolute and relative shelf position may strongly affect consumer choices. In this paper, we examine whether and how such shelf effects translate into an online grocery context. We find that a product's choice probability increases when presented on the first screen or located near focal items - especially when the latter are out-of-stock. These primacy and proximity effects have a stronger impact on choice decisions when assortments are more difficult to evaluate and when a clear shelf organization facilitates the use of shelf-based choice heuristics.
\end{abstract}

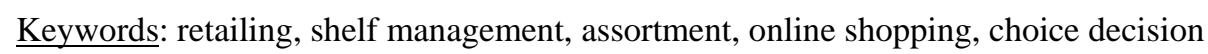

The Internet revolution has initiated a new era in which online shopping is a well-accepted way of purchasing products. Previous research examined the effects of unique online store characteristics, such as interactive decision aids and more flexible customization procedures (e.g. Senecal and Nantel 2004; Zhang and Krishnamurthi 2004). Less attention has been paid to the equally intriguing question whether traditional marketing mix instruments affect online purchase decisions to the same extent and in the same way. A number of studies indicate, though, that online shoppers may react differently to marketing mix instruments such as price and brand name (e.g. Andrews and Currim 2004; Degeratu, Rangaswamy and Wu 2000). 
Given the differences in store environment, there are reasons to expect even stronger divergence in responses to merchandising instruments like shelf display (Liang and Lai 2002). For one, in contrast to traditional stores, online stores typically allocate only one facing to each product, thereby eliminating shelf space allocation effects. Second, search processes are greatly facilitated by the small and easily examinable electronic shelves. Limited eye movements and simple scrolling across screens may suffice to scan the entire assortment. As a result, shelf position may be less effective to draw customer attention to specific products. This even led some authors to conclude that shelf management - though a dominant concern in traditional retail settings - becomes irrelevant in virtual stores (e.g. Yrjölä 2001; Menon and Kahn 2002). Yet, our study suggests that online shelf display may, in its own way, affect consumers' shopping decisions. As explained below, the order in which products are displayed and their position relative to other items may still play an important role in directing customer attention and guiding online choice decisions.

Up till now, systematic analysis of online shelf effects seems to be lacking. This research is a first step towards closing this gap. We examine whether traditional shelf effects prevail for online choices and - if so - how they translate to a virtual store context. In line with previous merchandising studies, we focus on shelf effects of fast moving consumer goods (fmcg), for which consumers often rely on simplifying choice heuristics. Using an online shopping experiment, we also provide indications on the drivers and magnitude of online shelf effects and suggest guidelines for improved shelf management. In the following section, we briefly review the traditional shelf literature and develop hypotheses on online shelf effects. Next, we describe the experiment and model used to test these effects. We then discuss implications for virtual shelf management and indicate directions for future research. 


\section{Traditional and online shelf effects}

\subsection{Traditional shelf effects}

The impact of shelf display on consumers' choice decisions in brick-and-mortar grocery stores is widely supported in the literature. Items are more likely to be chosen when they receive more shelf space (more facings) or are placed on more prominent shelf positions (Desmet and Renaudin 1998; Drèze, Hoch and Purk 1994). In terms of absolute shelf placement, vertical shelf position appears to have the strongest effect: products placed at eyeor hand-level having a significantly higher probability of being selected (Corstjens and Corstjens 1995; Campo and Gijsbrechts 2005). The impact of horizontal shelf position is less pronounced, and results seemed inconclusive at first as to which position is best (Drèze et al. 1994). Recent research suggests, though, that much depends on the entrance point of the shelf: in line with the primacy effect observed in communication literature, early encountered items appear more likely to be chosen (Broere, Van Gensink and Van Oostrom 1999). Finally, a product's relative shelf position may also affect its choice probability: placement near focal (e.g. highly-preferred) items increasing the probability that consumers will notice and select the product (Simonson and Winer 1992).

These shelf effects appear especially important when consumers are not highly involved with the purchase decision, are pressed for time and/or face comprehensive shopping tasks. In such situations, consumers often pursue satisfying rather than utility maximizing purchase decisions (Hoyer 1984). Shelf display may in this case play an important role in attracting customer attention and serve as a cue to simplify consumers’ choice decisions.

Products with more facings or placed on more prominent shelf positions are more likely to be noticed by consumers or catch attention first. Sequence of attention is especially important 
when consumers seek a satisfying and effortless solution. In this case, they will often stop their search procedure once a suitable product is found (Simonson 1999). Even when the search process continues, products encountered in a later stage may receive less attention: consumers having settled for a specific product and merely scanning subsequent items to justify their choice. The probability that an item is chosen thus depends on where consumers start their search. This may be the shelf area that first catches their attention (triggered e.g. by the number of facings, point of shelf entrance or vertical shelf position), or the area containing the most salient (e.g. highly-preferred) item. In addition to these attention-steering effects, shelf display may provide cues signaling product attractiveness: more popular items often receiving more shelf space and/or more prominent shelf positions.

\subsection{Online shelf effects}

A key question is whether and how these traditional shelf effects translate into online settings. Based on the differences between virtual and physical store shelves, we expect shelf space and vertical shelf position (eye-level) to play no or only a minor role in online settings. First, in contrast to traditional stores, online stores typically allocate only one facing to each item, making the number of facings a non-issue. Second, since all products are practically placed at eye-level when displayed on a small computer screen, vertical shelf position may no longer drive customer attention. Results from the communication literature seem to confirm this: advertisements in comparable - small and 2-D - media do not attract substantially more attention when placed on specific on-page positions (Hanssens and Weitz 1988). This is especially true in media used for product selection such as catalogues and store flyers (Nagelkerke 2004), which provide a quick and easy overview, and where consumers use many different starting points and scanning procedures (see e.g. Monk 1984). 
In contrast, we expect sequence effects - triggered in traditional stores by horizontal shelf positions - to remain relevant in virtual stores. First, because of the absence of physical space constraints, online assortments are often quite large and require more than one screen to display all items. Second, while browsing online shelves entails less effort than searching physical store shelves, this does not imply that online customers are oblivious to search costs. Being typically convenience-oriented, online shoppers may be equally reluctant to engage in a complete category search, even if they only have to scroll between different screens (Wu and Rangaswamy 2003; Kumar, Smith and Bannerjee 2004). Based on the traditional store shelf literature, we expect that products encountered earlier on in the search process will receive more attention (primacy effect), and hence, have a higher probability of being chosen. Yet, in contrast to traditional stores, online stores have a fixed entrance point. Therefore, we expect, in the same line as cover page positions enhance ad visibility (Gijsbrechts, Campo and Goossens 2003), that placement on the first screen entails substantially higher customer attention and choice probabilities. Thus:

\section{$H_{1}$ (Shelf sequence effect): Items displayed on the first screen of an online store have a higher probability of being chosen.}

Previous research indicates that consumers - once they fixed their attention on a part of the shelf - continue to focus on the subset of items displayed on that particular shelf section (see Hoch, Bradlow and Wansink 1999 and Simonson and Winer 1992 for a traditional; and Hong, Thong and Tam 2004-5 for an online shopping context). This search behavior may be driven by a desire to simplify the choice process as well as by the perception that more closely positioned items are more similar (Morales et al. 2005). We therefore expect that online shoppers will confine their search to the shelf section containing their focal item. Thus: 
$\mathrm{H}_{2}$ (Proximity effect): Items located next to a consumer's focal item have a higher probability of being chosen.

These shelf sequence $\left(\mathrm{H}_{1}\right)$ and proximity $\left(\mathrm{H}_{2}\right)$ effects are a direct result of the consumers' pursuit of satisfying and effortless solutions, which trigger the need for simplifying choice heuristics. As indicated above, recourse to such heuristics becomes more likely for complicated (yet low-involvement) shopping tasks. Previous research suggests that assortments are more difficult to evaluate when they comprise a larger number of items (assortment size; Broniarczyk, Hoyer and McAlister 1998) and/or when items are displayed in a disorganized way (assortment structure; Hoch et al. 1999; Drèze et al. 1994). Hence:

$H_{1 a}$ : A first-screen shelf position will have a stronger positive effect on an item's choice probability when the product assortment is larger.

$H_{2 a}$ : Proximity to focal items will have a stronger positive effect on an item's choice probability when the product assortment is larger.

$H_{1 b}$ : A first-screen shelf position will have a stronger positive effect on an item's choice probability when products are displayed in a disorganized way.

$H_{2 b}$ : Proximity to focal items will have a stronger positive effect on an item's choice probability when products are displayed in a disorganized way.

\section{Methodology}

\subsection{Experimental data}

Data were collected by means of a realistic online store experiment. This allows to manipulate treatment variables like shelf display and assortment, while controlling for extraneous influences such as promotions (Campo and Gijsbrechts 2005). There is growing evidence that computer simulated shopping experiments provide highly realistic buying behavior data, 
especially when decision cues mimic those of the real store environment (Burke et al. 1992; Campo, Gijsbrechts and Guerra 1999). This particularly holds in our study, where we used the site of an existing e-grocery store as a starting point ${ }^{1}$. We also used scanned pictures of actual products to facilitate visual product recognition and included the possibility to retrieve additional product information.

The computer experiment comprised: (1) a pre-purchase questionnaire to collect consumer background data, (2) a purchase simulation module and (3) a post-purchase questionnaire on the decision making process and virtual store experiences. Respondents were asked to make online purchases during six fictitious weeks ${ }^{2}$ for 2 product categories (margarine and cereals). To enhance the realism of purchase decisions, consumers were informed about their home inventory levels (computed on the basis of previous purchases and reported consumption rates) and were explicitly told they were not obliged to buy on every (fictitious) shopping trip.

In addition, like real online shopping environments, our virtual store exhibited stock-outs - at a realistic average of $8 \%$ of the products in the category (Sloot, Verhoef and Franses 2005). The occurrence of stock-outs was uniformly distributed over weeks, low and high share items and attribute levels (brands, flavors, size). The stock-out products remained visible on the screen, with a 'flag' signaling unavailability. Apart from enhancing realism, these stock-out occurrences allow for a more in-depth exploration of proximity effects - as explained below.

Absolute and relative shelf position was manipulated through changes in shelf arrangement: by brand or by flavor/type (in practice, the most commonly used arrangements). Consumers were randomly assigned to one of both arrangements. Depending on the shelf arrangement, 
on-screen positions, order of appearance and product adjacencies differed. In addition, the type of shelf arrangement was expected to influence shelf organization perceptions.

Assortment size manipulations were guided by retailer practices: brand and flavor being the predominant attributes along which assortments can be extended (Boatwright and Nunes 2001). Subjects were randomly assigned to one of three different assortments: (1) a limited assortment, (2) an assortment extended with flavors and (3) an assortment extended with brands. Table 1 gives an overview - for each category and assortment - of the number of products, respondents and purchase occasions.

\section{$<$ insert table 1 $>$}

To get a representative sample, we used e-mail addresses from a list broker (addresses selected on the basis of demographic and purchase behavior information) and from the full staff of the university (including technical and administrative staff). For each address, participation was requested of the household member typically in charge of grocery shopping $^{3} .17 \%$ of the respondents completed the purchase simulation, a response rate that compares favorably to other online surveys (e.g. Verhoef and Langerak 2001). The sociodemographic characteristics of our sample matched the online grocery sample profiles in other studies (e.g. Degeratu et al. 2000; Rohm and Swaminathan 2002).

\subsection{Model structure}

To test the hypotheses, we introduced shelf placement variables in a traditional multinomial logit (MNL) model. Specifically, our choice utilities take the following form:

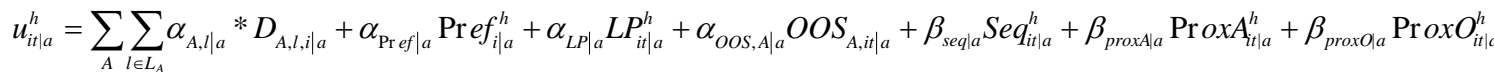

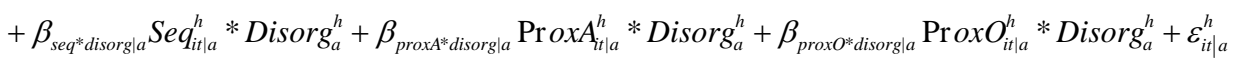

where $\mathrm{u}_{\mathrm{it|a}}^{\mathrm{h}}=$ choice utility of item i for household h facing assortment a at time $\mathrm{t}$ and $\varepsilon_{\mathrm{it|a}}^{\mathrm{h}}=$ random (extreme value distributed) error component. 
The first set of variables consists of 'traditional' household/item variables: attribute-specific

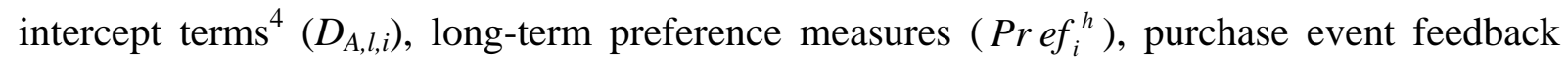
variables $\left(L P_{i t}^{h}\right)$ and attribute-specific stock-out asymmetry variables $\left(O O S_{A, i t}\right)$ (see table 2). The latter capture possible non-IIA choice shifts triggered by stock-outs (see Campo, Gijsbrechts and Nisol 2003). A positive (negative) coefficient indicates a tendency to switch to (away from) alternatives with the same attribute in case of a stock-out.

<insert table 2>

The sequence variable (Seq) is a dummy variable indicating whether or not item i is displayed on the first screen, a position expected to enhance the item's choice probability $\left(\mathrm{H}_{1}: \beta_{\text {seq }}>0\right)$. Relative shelf placement effects are captured by the proximity variables (ProxA and ProxO). These variables determine whether an item is positioned next to the respondent's focal item(s). Focal items are identified from the post-purchase questionnaire, based on long-term item preference. If several items are marked as focal (i.e. Pref $>0$ ), these items receive weights according to reported preference shares (see table 2). Following $\mathrm{H}_{2}$, adjacency to focal products enhances attention and increases choice probability $\left(\mathrm{H}_{2}: \beta_{\text {prox }}>0\right)$. While such proximity effects may already be found when the focal item is available, we expect them to be particularly pronounced when the focal item is out-of-stock, forcing consumers to adjust their choice. To explore this phenomenon, we introduce two separate proximity variables: ProxA (activated when a focal item is adjacent to product i and available) and ProxO (activated when a focal item is adjacent to product i and out-of-stock), and expect $\beta_{\text {proxo }}>\beta_{\text {proxA }}$.

The last three terms of equation (1) capture interaction effects between sequence/proximity variables and perceived degree of shelf organization (as reported in the post-purchase questionnaire $)^{5}$. As indicated in $\mathrm{H}_{1 \mathrm{~b}}$ and $\mathrm{H}_{2 \mathrm{~b}}$, we expect disorganized displays to stimulate the use of shelf-based simplifying choice heuristics. To test the moderating effect of assortment 
size $\left(\mathrm{H}_{1 \mathrm{a}}\right.$ and $\left.\mathrm{H}_{2 \mathrm{a}}\right)$, parameters of the shelf-based variables are allowed to vary across assortments, as is explained in more detail below.

\subsection{Estimation}

In each category, we estimate the choice model across the three assortments:

$p_{i t \mid a}^{h}=\frac{\exp \left\lfloor\mu_{a}\left(u_{i t \mid a}^{h}\right)\right\rfloor}{\sum_{j \in C_{t \mid a}^{h}} \exp \left[\mu_{a}\left(u_{j \mid t a}^{h}\right)\right]}$ for $i \in C_{a}^{h}$

with $p_{i t \mid a}^{h}=$ the probability that household h chooses item i facing assortment a at time $\mathrm{t}, \mathrm{u}_{\mathrm{it} \mid \mathrm{a}}^{\mathrm{h}}=$ the choice utility of item i for household h facing assortment a at time t, $C_{t \mid a}^{h}=$ set of category items available to household $\mathrm{h}$ within assortment a at time $\mathrm{t}$ and $\mu_{a}=$ Gumbel scale factor.

As suggested by Swait and Andrews (2003), we allow the scale factors $\mu_{a}$ and key utility parameters - including shelf effects - to differ between assortments ${ }^{6}$. For identification purposes, the scale factor of the first (limited) assortment is normalized to one ( $\mu_{1}=1$ ) (cf. Andrews and Currim 2002; Swait and Louvière 1993). To accommodate household heterogeneity, we opt for a continuous mixture approach with normally distributed parameters across households (McFadden and Train 2000). As suggested by Train (2001), we do not introduce random effects for attribute-specific constants ${ }^{7}$ or for variables that themselves already capture preference heterogeneity such as the LT preference measure and proximity variables. We estimate the mixed MNL (MMNL) model through simulated maximum likelihood using the quasi-random Monte Carlo (or Halton) method (Bhat 2001).

\section{Estimation results}

Table 3 presents, per category, the estimation results for a model with main shelf sequence and proximity effects (panel a) and a model where we add interaction effects between shelf sequence/proximity and perceived degree of shelf organization (panel b). For both models and categories, coefficients of the non-shelf-related variables (attribute constants, item preference, last purchase, stock-out asymmetry) are significant in the majority of cases and have the 
expected sign. Below, we first discuss the main effects of shelf sequence/proximity variables, and then indicate how these effects depend on the perceived degree of shelf organization. <insert table 3>

Main shelf effects. As shown in panel a of table 3, the sequence variable has a positive and significant impact in assortment 2 for margarine $\left(\beta_{\text {seq } \mid 2}=.43, \mathrm{p}<.05\right)$ and assortment 3 for cereals $\left(\beta_{\text {seq } 3}=.47, \mathrm{p}^{<.05}\right)$. In both categories, we thus find evidence of a primacy effect (support $\mathrm{H}_{1}$ ). Note that for margarine in assortment 1, all items are visible on one screen, eliminating possible first screen effects. Within the assortments where this parameter is significant, first-screen alternatives experience an important increase in choice probability: on average $13.39 \%$ for margarine (assortment 2) and 16.08\% for cereals (assortment 3).

Interestingly, a highly similar pattern is observed for the proximity effects. Being adjacent to a focal product significantly increases an item's choice probability in assortment 2 for margarine $\left(\beta_{\text {proxo|2 }}=1.06, \quad \mathrm{p}<.01 ; \beta_{\text {proxA|2 }}=.86, \quad \mathrm{p}<.01\right)$ and assortment 3 for cereals $\left(\beta_{\text {proxo } \mid 3}=3.80, \mathrm{p}<.01 ; \beta_{\text {proxA } \mid 3}=1.72, \mathrm{p}<.01\right)$. This indicates that consumers tend to fix their attention to the shelf area containing their focal item and are more likely to select a proximate item rather than a distant one, supporting $\mathrm{H}_{2}$. In addition, the proximity effect reveals much stronger when the focal item is unavailable $\left(\beta_{\text {proxo }}>\beta_{\text {proxA }}\right)$. Results for assortment 1 and 2 for cereals point in the same direction: a position near focal items only increases a product's choice probability when these focal items are out-of-stock $\left(\beta_{\text {proxo } \mid 1}=1.98, \mathrm{p}<.01 ; \beta_{\text {proxo|2 }}=.35\right.$, $\mathrm{p}<.01$ ). When significant, proximity effects are substantial: items close to unavailable (available) focal items having, on average, 9.86\% (8.51\%) (margarine, assortment 2), 21.70\% (n.s.) (cereals, assortment 1), 7.84\% (n.s.) (cereals, assortment 2) and 41.70\% (18.90\%) (cereals, assortment 3) higher propensities of being selected. 
Moderating effect of assortment size. The previous results already demonstrate that sequence and proximity effects may vary across assortments. Yet, the expectation that larger assortments are more difficult to evaluate, and will for this reason stimulate the use of shelfbased choice heuristics $\left(\mathrm{H}_{1 \mathrm{a}}\right.$ and $\mathrm{H}_{2 \mathrm{a}}$ ), is supported for one of the large assortments only (assortment 2 for margarine and assortment 3 for cereals). ANOVA-analyses on assortment differences in ease-of-processing scores ${ }^{8}$ (captured in the post-purchase questionnaire) help to better understand what is driving the results. Table 4 indicates that significant shelf effects do prevail in the more difficult-to-evaluate assortments. This is in line with the intuition behind $\mathrm{H}_{1 \mathrm{a}}$ and $\mathrm{H}_{2 \mathrm{a}}$ : shelf-based heuristics being used more often in complex choice situations. However, ease of processing is not driven by assortment size but rather by composition: assortments extended along the most important product attribute (brand for margarine and flavor for cereals ${ }^{9}$ ) facilitate the selection process (Boatwright and Nunes 2001) and reduce the need to rely on simplifying, shelf-based choice heuristics.

<insert table 4>

Interaction effect of perceived shelf organization. Based on panel b of table 3 and using the Jaccard, Turrisi and Wan (1990) test of interaction effects, sequence and proximity effects are only significant at low levels of the perceived shelf organization variable. So, in contrast to $\mathrm{H}_{1 \mathrm{~b}}$ and $\mathrm{H}_{2 \mathrm{~b}}$, we find that sequence and proximity more strongly affect customer choices when the shelf is perceived to be well-organized. This surprising result can be explained in two ways. First, manipulation checks indicated that - while there is sufficient variation in perceived degree of shelf organization - few consumers appear to consider the shelf as really disorganized (heavily skewed variable towards the 'organized' side ${ }^{10}$ ). This may be a result of the fact that the shelf was always organized along main product attributes: brand or flavor. Second, more clearly structured shelves may increase consumers' confidence in a satisfying outcome of shelf-based choice heuristics and may facilitate holistic information processing 
(Hoch et al. 1999). As such, consumers can first scan the shelf to locate subsections containing the most interesting items and next make a final choice from the limited set of items positioned within these subsections (Morales et al. 2005; Hong et al. 2004-5).

Robustness checks. To verify the validity of our findings, we conducted several robustness checks. First, we tested alternative operationalizations of the sequence effect. Replacing the first screen definition by a count variable (reflecting the serial order in which products are encountered when consumers scroll on to subsequent screens) did not produce any improvement in model fit. We also added a last screen variable, which turned out to have a negative effect, confirming that primacy effects are more important than recency effects. Second, in addition to the sequence variable (capturing across screen placement), we inserted an on-shelf position variable, capturing the placement of products on the first screen. We tested several alternatives, checking whether items presented on (i) top rows, (ii) middle rows (the counterpart of eye-/hand-level) or (ii) top-left positions had higher choice propensities. As expected, none of these alternative on-screen variables improved model fit or face validity. Third, to make sure that our proximity or sequence effects were not an artifact of the way the shelf was arranged (by brand or flavor), we tested a model with interaction effects between attribute-specific constants and/or attribute stock-out asymmetry on the one hand and shelf arrangement on the other hand. We also tested interactions between the sequence/proximity variables and shelf arrangement. Most of these adjustments revealed non-significant and for none of the cases model fit improved ${ }^{11}$. This confirms that our sequence and proximity variables do reflect primacy and product adjacency effects - not brand or variety preferences.

\section{Discussion}


Our results show that, despite debates about the ease of searching on the Internet, shelf management remains an important issue for online grocery stores. First, we find that across screen placement may strongly affect choices. First-screen alternatives are more likely to be selected, as consumers start to acquire and process information on that screen and - for fmcg - search for a satisfying rather than an optimizing solution (primacy-effect). The fight for shelf space thus becomes a fight for 'first screen placement', manufacturers having an interest in procuring positions on the initial category screen to highlight specific (e.g. higher-margin, private label) items. A possible caveat is that many e-grocery sites offer the possibility to change the shelf layout. Yet, consumers do see the default/start option first, and like previous research (Wu and Rangaswamy 2003), our results show that they tend to stay with this option. Second, even though the absolute placement of products on a screen is not influential, their placement relative to other items is. Once consumers focus on a particular shelf section (containing their favorite item), they are likely to stay within that section. Especially when the focal item is out-of-stock, there is a strong positive effect on choice probabilities of closely positioned alternatives. But even if the favorite product is available, we find that other items may significantly benefit from being placed adjacent to it.

Third, while their potential impact is substantial, sequence and proximity effects are not always active. Our study clearly highlights conditions under which shelf effects do prevail. For one, consumers reveal more inclined to adopt shelf-based heuristics when they experience more difficulty in finding and choosing an item from the assortment. Our results indicate that unavailability of key product attributes rather than assortment size complicates the decision process - an observation consistent with the results of Boatwright and Nunes (2001). Interestingly, rather than making shelf-based heuristics redundant, we also find that a transparent shelf structure increases consumers' confidence in their outcome and hence, stimulates their use. 
Clearly, our research has several limitations. First, using an experiment may have entailed biases due to, for instance, the absence of budget/time constraints and relatively easy shopping task (two categories). One could argue that this makes our test a conservative one: consumers' tendency to use heuristics probably increasing when they have a long shopping list and/or are really pressed for time. At the same time, the limited number of shopping occasions made dynamic elements like store familiarity difficult to account for. Future realtime longitudinal studies could shed more light on the use of shelf-based cues over time.

Second, we manipulated only two possible assortment extensions (brand or flavor) and considered assortments that remained modest in size. The fact that we do find evidence of shelf-based heuristics in such a setting is, again, encouraging. Even so, more extensive analysis is needed to examine whether and how assortment differences (e.g. more variation in assortment size/composition), in a wider range of categories, affect perceived decision difficulty and the use of shelf-based heuristics. In addition, our results apply to grocery etailers (where consumers typically have directed search goals) and not necessarily to all online e-tailers. Investigating the impact of shelf-based heuristics in another (non-frequently purchased goods) environment (where different types of shopping goals stand out, e.g. browsing tasks, see Hong et al. 2004-5) might be a useful extension.

Third, while our experiment provides interesting findings, it also raises new issues. For one, the absence of significant 'on screen' effects may stem from the fact that brand stimulus characteristics that we do not control for (e.g. package color, van der Lans, Pieters and Wedel 2005), dominate on-screen salience, and blur consumers' systematic search patterns. Experimental approaches that allow for closer analysis of consumers' decision processes (e.g. decision time and/or eye movements) may shed more light on these interesting issues. Such analyses could also provide a better insight into the reasons underlying the primacy effect: a 
narrowing down of the consideration set or a reduction in degree of consideration. In addition, it would be worthwhile to explore what determines shelf (dis-)organization perceptions, which in our study did not relate to type of shelf arrangement or congruency between the shelf arrangement and consumers’ dominant choice criteria.

Finally, the finding that online grocery shoppers are susceptible to shelf placement effects opens up exciting new research possibilities: the influence of typical online instruments such as display customization, cross-merchandising or the availability of previous shopping lists - being high on the research agenda. 


\section{Notes}

${ }^{1}$ The software and the experimental site were developed by Hypervision, the software company responsible for the e-grocery site. Some adjustments were made to fit our experimental design (e.g. absence of promotions).

${ }^{2}$ Previous research has demonstrated that the time compression of several fictitious shopping weeks into one experimental session does not preclude realistic dynamic purchase patterns (Burke et al. 1992).

3 To stimulate participation without endangering the representativeness of the sample, participants were made eligible for some small rewards on a lottery basis. The probability of receiving the reward was not linked to task performance but was only used to enhance response rates. The reward was kept sufficiently small to avoid any effect on sample composition or simulated purchase behavior. In line with previous computer simulated shopping experiments (e.g. Burke et al. 1999; Campo et al. 1999), we rather tried to help and stimulate respondents in imitating their normal buying behavior by providing clear task instructions and realistic decision cues (see section 2.1).

${ }^{4}$ Traditionally, price would also be included in the utility function. However, due to our experimental setup, prices do not change over time and are, therefore, strongly linked to the set of attributes describing the SKU. Estimation of a model incorporating both SKU attribute constants and price would, under these circumstances, lead to serious estimation problems caused by collinearity between both sets of variables.

${ }^{5}$ Two alternative measures of shelf organization were tested: (i) type of shelf arrangement (by brand or by flavor) and (ii) congruency measures (Morales et al. 2005), indicating whether shelves were arranged along the consumer's dominant choice criterion or not (choice criteria weights were derived from the post-purchase questionnaire). In both cases, the introduction of the interaction terms did not provide a significant improvement in model fit. Further analysis revealed that - contrary to expectations - perceived degree of shelf organization (as reported by respondents) is only very weakly related to more objective measures such as the type of shelf arrangement and the degree of (shelf-choice) congruency. Like previous studies (e.g. Drèze et al. 1994), this points to the need for further research on the underlying factors of shelf organization perceptions.

${ }^{6}$ As argued before, consumers are more likely to turn to task-simplifying tactics when they have to search a (replacement) product in a large compared to a small assortment. We expect differences with respect to the sequence, proximity and asymmetric switching variables between assortments: the effects being (more) significant in a large than in a small assortment $\left(\mathrm{H}_{1 \mathrm{a}}\right.$ and $\left.\mathrm{H}_{2 \mathrm{a}}\right)$. Although we did not explicitly include hypotheses with respect to the moderating effect of assortment size on the tendency to asymmetrically switch towards items with specific attributes, it is not inconceivable that a similar logic holds for these asymmetry variables. The probability that consumers will focus on key product attributes as a heuristic to make easy and effortless decisions is more likely in a large than in a small assortment. Not only assortment size, also composition might affect the tendency to turn to specific asymmetric switching heuristics. For these reasons, we decided not to constrain asymmetric switching variables to be equal across assortments. In contrast, the tendency to have a LT preference or to repurchase the same item is a personality trait that is expected to be prevalent across assortments (cf. Andrews and Currim 2002). The validity of these choices was confirmed by robustness checks that explicitly tested whether variables should be pooled or not.

${ }^{7}$ There are various reasons why we decided to keep attribute-specific coefficients constant. First, it is shown that mixed logit models have a tendency to be unstable when all coefficients are allowed to vary (Train 1999). Models where all coefficients varied did indeed not converge in any reasonable number of iterations. Fixing the attribute-specific coefficients resolved this instability. Second, Train (2001) has indicated that the mixture might be empirically unidentifiable in a model where, next to final iid extreme value terms, the item-specific dummy coefficients are assumed to be random. Including a similar distribution (which is the case for the normal and extreme value distribution) results in unstable estimations because the final iid extreme-value terms in a model with item-specific constants already constitute the random portion of these constants. Robustness checks explicitly testing whether or not variables should be fixed, confirmed the validity of our choices.

${ }^{8}$ Ease of processing had a Cronbach alpha of 0.814 (0.875) for margarine (cereals). The factor structure was confirmed by a principal components analysis.

${ }^{9}$ In line with previous results, we find that the type of attribute guiding customer choices, differs between categories (e.g. Campo et al. 2003). In the cereals category, $70 \%$ of the respondents indicate, in the postpurchase questionnaire, to place strong emphasis on flavor, while only $44 \%$ of the shoppers mention this criterion as important when selecting margarine. Margarine choices, in contrast, are strongly guided by brand cues: $49 \%$ of margarine-buyers mention this attribute as important while only $17 \%$ does so for cereals.

10 Re-estimating the model with a transformation of the perceived shelf organization variable to achieve normality did not change the results.

11 Note that the stock-out asymmetry variables already account for the fact that, when facing stock-outs, consumers may more readily switch to items of the same size, brand and/or flavor. Proximity effects thus reflect the impact of product adjacencies over and above these attribute-driven switches. The robustness checks provide an additional guarantee that it is proximity, and not attribute-based shelf arrangement, that drives the results. 


\section{References}

Andrews, R.L., \& Currim, I.S. (2002). Identifying segments with identical choice behaviors across product categories: An intercategory logit mixture model. International Journal of Research in Marketing, 19 (1), 65-79.

Andrews, R.L., \& Currim, I.S. (2004). Behavioral differences between consumers attracted to shopping online versus traditional supermarkets: Implications for enterprise design and marketing strategy. International Journal of Internet Marketing and Advertising, 1 (1), 38-61.

Bhat, C.R. (2001). Quasi-random maximum simulated likelihood estimation of the mixed multinomial logit model. Transportation Research, 35B (7), 677-695.

Boatwright, P., \& Nunes, J.C. (2001). Reducing assortment: An attribute-based approach. Journal of Marketing, 65 (3), 50-63.

Broniarczyk, S.M., Hoyer, W.D., \& McAlister, L. (1998). Consumers’ perceptions of the assortment offered in a grocery category: The impact of item reduction. Journal of Marketing Research, 35 (2), 166-167.

Broere, Van Gensink \& Van Oostrom (1999). De relatie tussen looprichting en aankoopgedrag. Erasmus Food Management Institute, EFMI 2001-05. (in dutch)

Burke, R.R., Harlam, B.A., Kahn, B., \& Lodish, L.M. (1992). Comparing dynamic consumer choice in real and computer-simulated environments. Journal of Consumer Research, 19 (1), 71 -82.

Campo, K., \& Gijsbrechts, E. (2005). Retail assortment, shelf and stockout management: Issues, interplay and future challenges. Applied Stochastic Models in Business and Industry edited by Bemmaor, A.C. \& Franses, P.H., 21 (3).

Campo, K., Gijsbrechts, E., \& Guerra, F. (1999). Computer simulated shopping experiments for analyzing dynamic purchasing patterns: validation and guidelines. Journal of Empirical Generalisations in Marketing Science 4, 22-61.

Campo, K., Gijsbrechts, E., \& Nisol, P. (2003). The impact of retailer stockouts on whether, how much and what to buy. International Journal of Research in Marketing, 20 (3), 273-286.

Corstjens, J., \& Corstjens, M. (1995). Store wars: The battle for mindspace and shelfspace. Wiley: Chichester.

Degeratu, A.M., Rangaswamy, A., \& Wu, J. (2000). Consumer choice behavior in online and traditional supermarkets: The effects of brand name, price, and other search attributes. International Journal of Research in Marketing, 17 (1), 55-78.

Desmet, P. \& Renaudin, V. (1998). Estimation of product category sales responsiveness to allocated shelf space. International Journal of Research in Marketing, 15 (5), 443-457.

Drèze, X., Hoch, S.J. \& Purk, M.E. (1994). Shelf management and space elasticity. Journal of Retailing, 70 (4), 301-326.

Gijsbrechts, E., Campo, K, \& Goossens, T. (2003). The impact of store flyers on store sales and store traffic: A geomarketing approach. Journal of Retailing, 79 (1), 1-16.

Hanssens, D.M., \& Weitz, B.A. (1980). The effectiveness of industrial print advertisements across product categories. Journal of Marketing Research, 17 (2) 294-306.

Hoch, S.J., Bradlow, E.T., \& Wansink, B. (1999). The variety of an assortment. Marketing Science, 18 (4), 527577.

Hong, W., Thong, J.Y.L., \& Tam, K.Y.(2004/5). The effects of information format and shopping task on consumers' online shopping behavior: A cognitive fit perspective. Journal of Management Information systems, 21 (3), 149-184.

Hoyer, W.D. (1984). An examination of consumer decision making for a common, repeat-purchase product. Journal of Consumer Research, 11 (3), 822-829.

Jaccard, J., Robert T. and Choi W. (1990), Interaction effects in multiple regression. Sage: Newbury Park, California. 
Kumar, R.L., Smith, M.A., \& Bannerjee, S. (2004). User interface features influencing overall ease of use and personalization. Information \& Management, 41 (3), 289-302.

Liang, T.-P., \& Lai, H.-J. (2002). Effect of store design on consumer purchases: An empirical study of on-line bookstores. Information \& Management, 39 (6), 431-444.

McFadden, D., \& Train, K.E. (2000). Mixed MNL models for discrete response. Journal of Applied Econometrics, 15 (5), 447-470.

Menon, S., \& Kahn, B.E. (2002). Cross-category effects of induced arousal and pleasure on the Internet shopping experience. Journal of Retailing, 78 (1), 31-40.

Monk, T. (1984). Search, in Sustained Attention in Human Performance, ed. J.S. Warm. New York: Wiley, 293321.

Morales, D., Kahn, B.E., McAlister, L. \& Broniarczyk, S.M. (2005). Perceptions of assortment variety: The effects of congruency between consumers' internal and retailers' external organization. Journal of Retailing, 81 (2), 159-169.

Nagelkerke, J. (2004). Towards fair manufacturer fees: Measuring the effectiveness of store flyer advertisement layout using panel data, Unpublished Dissertation, Tilburg University.

Rohm, A.J., \& Swaminathan, V. (2004). A typology of online shoppers based on shopping motivations. Journal of Business Research, 57 (7), 748-757.

Senecal, S., \& Nantel, J. (2004). The influence of online product recommendations on consumers' online choices. Journal of Retailing, 80 (2), 159-169.

Simonson, I. (1999). The effect of product assortment on buyer preferences. Journal of Retailing, 75 (3), $347-$ 370.

Simonson, I., \& Winer, R.S. (1992). The influence of purchase quantity and display format on consumer preference for variety. Journal of Consumer Research, 19 (1), 133-138.

Sloot, L.M., Verhoef, P.C., \& Franses, P.H. (2005). The impact of brand equity and the hedonic level of a product on consumer stock out reactions. Journal of Retailing, 81 (1), 14-35.

Swait, J., \& Andrews, R.L. (2003). Enriching scanner panel models with choice experiments. Marketing Science, 22 (4), 442-460.

Swait, J., \& Louvière, J. (1993). The role of the scale parameter in the estimation and comparison of multinomial logit models. Journal of Marketing Research, 30 (3), 305-315.

Train, K.E. (1999). Halton sequences for mixed logit. Working paper. Berkeley

Train, K.E. (2001). A comparison of hierarchical bayes and maximum simulated likelihood for mixed logit. Working paper. Berkeley

van der Lans, R., Pieters, R. \& Wedel, M. (2005). In search of the brand: A conceptual model and a first empirical study. Working paper. Tilburg: Tilburg University.

Verhoef, P., \& Langerak, F. (2001). Possible determinants of consumers' adoption of electronic grocery shopping in The Netherlands. Journal of Retailing and Consumer Services, 8 (5), 275-285.

Wu, J., \& Rangaswamy, A. (2003). A fuzzy set model of search and consideration with an application to an online market. Marketing Science, 22 (3), 411-434.

Yrölä, H. (2001). Physical distribution considerations for electronic grocery shopping. International Journal of Physical Distribution and Logistics Management, 31 (10), 746-761.

Zhang, J., \& Krishnamurthi, L. (2004). Customizing promotions in online stores. Marketing Science, 23 (4), 561578. 
Table 1: Descriptives for each assortment (margarine and cereals)

\begin{tabular}{|c|c|c|c|c|c|c|}
\hline & \multicolumn{3}{|c|}{ MARGARINE } & \multicolumn{3}{|c|}{ CEREALS } \\
\hline Attribute & $\begin{array}{l}\text { Ass } 1 \\
\text { (limited) }\end{array}$ & $\begin{array}{l}\text { Ass } 2 \text { (add new } \\
\text { flavors of existing } \\
\text { brands) }\end{array}$ & $\begin{array}{l}\text { Ass } 3 \text { (add new } \\
\text { brands of } \\
\text { existing flavors) }\end{array}$ & $\begin{array}{l}\text { Ass } 1 \\
\text { (limited) }\end{array}$ & $\begin{array}{l}\text { Ass } 2 \text { (add new } \\
\text { flavors of existing } \\
\text { brands) }\end{array}$ & $\begin{array}{l}\text { Ass } 3 \text { (add new } \\
\text { brands of existing } \\
\text { flavors) }\end{array}$ \\
\hline \multirow[t]{2}{*}{ Brand } & \multirow[t]{2}{*}{ Common $^{\mathrm{a}}$} & \multirow[t]{2}{*}{ Common } & Common & \multirow[t]{2}{*}{ Common } & \multirow[t]{2}{*}{ Common } & Common \\
\hline & & & Add new brands & & & Add new brands \\
\hline \multirow[t]{2}{*}{ Flavor } & \multirow[t]{2}{*}{ Common } & Common & \multirow[t]{2}{*}{ Common } & \multirow[t]{2}{*}{ Common } & Common & \multirow[t]{2}{*}{ Common } \\
\hline & & Add new flavors & & & Add new flavors & \\
\hline \# items & 11 & 19 & 17 & 21 & 32 & 46 \\
\hline \# resp & 105 & 116 & 100 & 81 & 97 & 87 \\
\hline $\begin{array}{l}\text { \# purchase } \\
\text { occasions }\end{array}$ & 275 & 279 & 278 & 271 & 261 & 281 \\
\hline
\end{tabular}

${ }^{\mathrm{a}}$ common refers to attribute levels that are present in all three assortments

Table 2: Variables in MNL choice model

\begin{tabular}{|c|c|}
\hline Variable & escription \\
\hline $\mathrm{A}$ & et of attributes relevant to the product category (e.g. brand, flavor, type and/or package size) \\
\hline $\mathrm{L}_{\mathrm{A}}$ & ndex set of levels relevant for attribute A (e.g. brand x, brand y, ...) \\
\hline $\mathrm{D}_{\mathrm{A}, \mathrm{l}, \mathrm{i}}$ & $\begin{array}{l}\text { Attribute-level dummy variable (equal to } 1 \text { if item } \mathrm{i} \text { is characterized by level } \mathrm{l} \text { on attribute } \mathrm{A}, 0 \\
\text { otherwise) }\end{array}$ \\
\hline $\operatorname{Pr} e f_{i}^{h}$ & $\begin{array}{l}\text { Long-term preference of household h for item i, measured as its 'purchase share' in the 12-month } \\
\text { period prior to the experiment (as reported in the post-purchase questionnaire) }\end{array}$ \\
\hline$L P_{i t}^{h}$ & $\begin{array}{l}\text { Purchase event feedback dummy variable (equal to } 1 \text { when item i was last purchased by } \\
\text { household h at time t, } 0 \text { otherwise) }\end{array}$ \\
\hline $\operatorname{OOS}_{A, i t}$ & $\begin{array}{l}\text { asymmetry variable for attribute A (equal to the number of alternatives similar to i on } \\
\text { A that are out-of-stock in t) }\end{array}$ \\
\hline $\operatorname{Seq}_{i t}^{h}$ & $\begin{array}{l}\text { Shelf sequence variable (equal to } 1 \text { if item i for household h is shown on the first screen at time t, } \\
0 \text { otherwise) }\end{array}$ \\
\hline $\operatorname{Pr} o x A_{i t}^{h}$ & $\begin{array}{l}\text { Proximity variable based on preference for items that are available during time } \mathrm{t} \text { (equal to the } \\
\text { weighted sum of the number of items } \mathrm{j} \text { that are positioned next to item } \mathrm{i} \text { at time } \mathrm{t} \text { for household } \mathrm{h} \text {, } \\
\text { with weights equal to the preference of household } \mathrm{h} \text { for item } \mathrm{j}\left(\operatorname{Pr} e f_{j}^{h}, \mathrm{j} \neq j_{\text {oos }}\right) \text { ) } \\
\operatorname{Pr} \mathrm{ox} A_{i t}^{h}=\sum_{j \neq j_{\text {oos }}} \operatorname{Pr} e f_{j}^{h} * A d j_{i-j, t}^{h} \\
\text { with } A d j_{i-j, t}^{h}=\text { adjacency dummy variable (equal to } 1 \text { if item } \mathrm{i} \text { is adjacent to item } \mathrm{j} \text { for } \\
\text { household h at time t, } 0 \text { otherwise) }\end{array}$ \\
\hline $\operatorname{Pr} o x O_{i t}^{h}$ & $\begin{array}{l}\text { Proximity variable based on preference for items that are unavailable during time t (equal to the } \\
\left.\text { weighted sum of the number of out-of-stock items ( } j_{\text {oos }}\right) \text { that are positioned next to item i at } \\
\text { time t for household h, with weights equal to the preference of household h for the stock-out item } \\
\left.\left(\operatorname{Pr} e f_{j_{o o s}}^{h}\right)\right) \\
\operatorname{Pr} o x O_{i t}^{h}=\sum_{j_{o o s}} \operatorname{Pr} e f_{j_{o o s}}^{h} * A d j_{i-j_{o o s}, t}^{h} \\
\text { with } A d j_{i-j_{o o s}, t}^{h}=\text { adjacency dummy variable (equal to } 1 \text { if item i is adjacent to stock-out item } \\
j_{o o s} \text { for household h at time t, } 0 \text { otherwise) }\end{array}$ \\
\hline Disorg $_{a}^{h}$ & the post-purchase questionnaire) \\
\hline
\end{tabular}

Table 4: ANOVA-results for the impact of assortment (margarine and cereals)

\begin{tabular}{|l|l|l|l|l|l|l|}
\hline Variable & \multicolumn{1}{|c|}{ Margarine } & \multicolumn{1}{c|}{ Cereals } \\
\cline { 2 - 7 } & $\begin{array}{c}\text { Ass 2 } \\
\text { Limited } \\
\text { Ext flavors }\end{array}$ & $\begin{array}{c}\text { Ass 3 } \\
\text { Ext brands }\end{array}$ & $\begin{array}{c}\text { Ass 1 } \\
\text { Limited }\end{array}$ & $\begin{array}{c}\text { Ass 2 } \\
\text { Ext flavors }\end{array}$ & $\begin{array}{c}\text { Ass 3 } \\
\text { Ext brands }\end{array}$ \\
\hline \# of items & 11 & 19 & 17 & 21 & 32 & 46 \\
\hline $\begin{array}{l}\text { Ease of } \\
\text { processing }\end{array}$ & 5.59 & 5.67 & $\mathbf{5 . 8 9}$ & 5.48 & $\mathbf{5 . 8 5}$ & 5.28 \\
\cline { 2 - 7 } & Significant difference: 1 \& 3, 2 \& 3 & Significant difference: 1 \& 2, 2 \& 3 \\
\hline
\end{tabular}


Table 3: Model estimation results ${ }^{\mathrm{a}}$

\begin{tabular}{|c|c|c|c|c|c|c|c|}
\hline \multicolumn{4}{|c|}{ Margarine } & \multicolumn{4}{|c|}{ Cereals } \\
\hline Variable & Assortment 1 & Assortment 2 & Assortment 3 & Variable & Assortment 1 & Assortment 2 & Assortment 3 \\
\hline \multicolumn{8}{|l|}{ PANEL A } \\
\hline Scale factor & [1.00] & $1.3319 * * *$ & $1.2861^{* * *}$ & Scale factor & [1.00] & $1.0877^{* * *}$ & $0.8136^{* * *}$ \\
\hline $\begin{array}{l}\text { Mean } \\
\text { Last purchase }\end{array}$ & $19938 * * *$ & {$[26555 * * *]^{\mathrm{b}}$} & {$[25642 * * *]^{\mathrm{b}}$} & $\begin{array}{l}\text { Mean } \\
\text { Last purchase }\end{array}$ & $06377 * * *$ & {$[06936 * * *]^{b}$} & \\
\hline $\begin{array}{l}\text { Last purcnase } \\
\text { Item preference }\end{array}$ & $2.9350 * * *$ & {$[3.9091 * * *]^{\mathrm{b}}$} & $\begin{array}{l}{\left[2.5642^{* * *}\right]^{\mathrm{o}}} \\
{\left[3.7747^{* * * *}\right]^{\mathrm{b}}}\end{array}$ & $\begin{array}{l}\text { Last purchase } \\
\text { Item preference }\end{array}$ & $\begin{array}{l}0.6377^{* * * *} \\
52162 * * *\end{array}$ & {$\left[0.6936^{* * *}\right]^{\circ}$} & {$[0.5188 * * *]^{0}$} \\
\hline Brand asymmetry & 0.3024 & $0.4201 * *$ & 0.5430 & Brand asymmetry & 0.0155 & 0.6193 & 0.0533 \\
\hline Size asymmetry & -0.0826 & -0.0886 & 0.0081 & Taste asymmetry & -0.0351 & $0.3031^{* *}$ & -0.1233 \\
\hline Sequence & & $0.4302 * *$ & -0.0883 & Type asymmetry & 0.3253 & -0.0557 & $0.3182 *$ \\
\hline Proximity (oos) & 0.8415 & $1.0628 * * *$ & 0.6424 & Sequence & -0.3019 & -0.0920 & $0.4670^{* *}$ \\
\hline Proximity (nt-oos) & 0.3906 & $0.8553^{* * *}$ & 0.4332 & Proximity (oos) & $1.9757 * * *$ & $0.3508^{* * *}$ & $3.8016^{* * *}$ \\
\hline Variances & & & & Proximity (nt-oos) & 0.8160 & 0.2817 & $1.7231^{* * *}$ \\
\hline Last purchase & $2.0506^{* * *}$ & $1.9053^{* * *}$ & $2.2458^{* * *}$ & Variances & & & \\
\hline Brand asymmetry & 0.0636 & 0.0625 & 0.0548 & Last purchase & $3.3527 * * *$ & $0.7272 * * *$ & $2.4716^{* * *}$ \\
\hline Size asymmetry & 0.0274 & 0.0157 & 0.0205 & Brand asymmetry & $0.4054^{*}$ & 0.4309 & 0.3532 \\
\hline Sequence & & 0.1138 & 0.1003 & Taste asymmetry & 0.2185 & 0.1428 & $0.4377^{* *}$ \\
\hline & & & & Type asymmetry & 0.1213 & $0.5004 * * *$ & 0.4327 \\
\hline & & & & Sequence & 0.6713 & 0.1138 & $0.9177^{* *}$ \\
\hline \multicolumn{8}{|l|}{ PANEL B } \\
\hline $\begin{array}{l}\text { Scale factor } \\
\text { Mean }\end{array}$ & [1.00] & & $1.2771^{* * *}$ & $\begin{array}{l}\text { Scale factor } \\
\text { Mean }\end{array}$ & [1.00] & $1.1164 * * *$ & $0.8257 * * *$ \\
\hline Last purchase & $2.0030 * * *$ & {$\left[2.7071^{* * *}\right]^{\mathrm{b}}$} & {$[2.5580 * * *]^{\mathrm{b}}$} & Last purchase & $0.6907 * * *$ & {$[0.7711 * * *]^{\mathrm{b}}$} & {$\left[0.5703^{* * *}\right]^{\mathrm{b}}$} \\
\hline Item preference & $2.9575^{* * *}$ & {$[3.9971 * * *]^{\mathrm{b}}$} & {$[3.7770 * * *]^{\mathrm{b}}$} & Item preference & $5.2086^{* * *}$ & {$[5.8149 * * *]^{b}$} & {$\left[4.3007^{* * *}\right]^{\mathrm{b}}$} \\
\hline Brand asymmetry & 0.3087 & $0.4208^{* *}$ & $0.5473^{*}$ & Brand asymmetry & -0.0375 & 0.5809 & 0.0431 \\
\hline Size asymmetry & -0.0588 & -0.1069 & 0.0012 & Taste asymmetry & -0.0495 & $0.2955^{* *}$ & -0.1657 \\
\hline Sequence & & 0.5548 & -0.1326 & Type asymmetry & 0.3364 & -0.0454 & $0.3407 *$ \\
\hline Sequence * Disorg & $--^{c}$ & $-0.0773^{\mathrm{d}}$ & $0.0948^{\mathrm{d}}$ & Sequence & -0.2857 & -0.0992 & 0.4116 \\
\hline & & $\rightarrow$ Sign. for 4 lowest & $\rightarrow$ n.s. & Sequence * Disorg & $-0.0012^{\mathrm{d}}$ & $0.0561^{\mathrm{d}}$ & $-0.1747^{\mathrm{d}}$ \\
\hline Proximity (oos) & 0.8699 & $\begin{array}{l}\text { scores Disorg } \\
1.0798\end{array}$ & 0.7218 & & $\rightarrow$ n.s. & $\rightarrow$ n.s. & $\begin{array}{l}\rightarrow \text { Sign. for } 4 \text { lowest scores } \\
\text { Disorg }\end{array}$ \\
\hline Proximity (oos) * Disorg & $-1.0183^{\mathrm{d}}$ & $-0.4757^{\mathrm{d}}$ & $0.5987^{\mathrm{d}}$ & Proximity (oos) & 1.9353 & 1.4376 & 3.6646 \\
\hline & $\rightarrow$ Sign. for 3 lowest & $\rightarrow$ Sign. for 3 lowest & $\rightarrow$ n.s. & Proximity (oos) * Disorg & $-1.8330^{\mathrm{d}}$ & $-0.2977^{d}$ & $-0.2340^{\mathrm{d}}$ \\
\hline Proximity (nt-oos) & 0.3766 & 0.8553 & 0.4076 & & $\begin{array}{l}\rightarrow \text { Sign. for } 3 \text { lowest } \\
\text { scores Disorg }\end{array}$ & $\begin{array}{l}\rightarrow \text { Sign. for 4lowest scores } \\
\text { Disorg }\end{array}$ & $\begin{array}{l}\rightarrow \text { Sign. for } 6 \text { lowest scores } \\
\text { Disorg }\end{array}$ \\
\hline Proximity (nt-oos) * Disorg & $-0.4736^{\mathrm{d}}$ & $-0.4783^{\mathrm{d}}$ & $-0.0371^{\mathrm{d}}$ & Proximity (nt-oos) & 0.8049 & 0.6608 & 1.6956 \\
\hline & $\rightarrow$ n.s. & $\rightarrow$ Sign. for 4 lowest & $\rightarrow$ n.s. & Proximity (nt-oos) * Disorg & $-0.2029^{d}$ & $0.0297^{\mathrm{d}}$ & $-0.1398^{\mathrm{d}}$ \\
\hline $\begin{array}{l}\text { Variances } \\
\text { Last purchase }\end{array}$ & & scores Disorg & & & $\rightarrow$ n.s. & $\rightarrow$ n.s. & $\rightarrow$ Sign. for 6 lowest scores \\
\hline & $2.0640^{* * *}$ & $1.9933^{* * *}$ & $2.2032^{* * *}$ & Variances & & & Disorg \\
\hline Brand asymmetry & 0.0370 & 0.1060 & 0.0005 & Last purchase & $3.2354^{* * *}$ & $0.8631 * *$ & $2.5170 * * *$ \\
\hline Size asymmetry & 0.0154 & 0.0028 & 0.0198 & Brand asymmetry & $0.3772 *$ & 0.3696 & 0.2335 \\
\hline Sequence & $-{ }^{c}$ & 0.1183 & 0.3209 & Taste asymmetry & 0.2420 & 0.1161 & $0.6068 * * *$ \\
\hline Sequence * Disorg & $-{ }^{c}$ & 0.0180 & 0.1095 & Type asymmetry & 0.1399 & $0.4570^{* *}$ & 0.3582 \\
\hline & & & & Sequence & 0.6713 & 0.5130 & $0.8788^{* *}$ \\
\hline & & & & Sequence * Disorg & 0.1481 & 0.1085 & 0.3418 \\
\hline
\end{tabular}

a Brand and flavor constants have been omitted from the table, but can be obtained from the authors on request. *** = sign. at $1 \%$ level; $* *=$ sign. at $5 \%$ level; $*=$ sign. at $10 \%$ level; 2 -tailed significance test, with exception of sequence and proximity variables, for which a 1-tailed test was applied.

b These coefficients are derived parameter estimates (found by multiplying the values for these variables by the relative scale parameter).

CIn assortment 1 (margarine), all alternatives are shown on the first page, implying that no first-screen effect could be estimated for this assortment.

$\mathrm{d}$ Because this is a moderating effect, the approach of Jaccard, Turrisi and Wan (1990) must be adopted. 